\title{
Leadership Behaviour Preferences of Student-Athletes: A Comparative Study of South Africa and India
}

\author{
Andile. Mji \\ Jhalukpreya. Surujlal \\ Tswane University of Technology \& North-West University Vaal Campus \\ E-mail:mjia@tut.ac.za/Babs.Surujlal@nwu.ac.za
}

Doi:10.5901/mjss.2013.v4n11p81

\begin{abstract}
The athlete-coach relationship is a vertical dyadic relationship in which the coach plays a critical leadership role. The direct influence of coaches on their athletes has been widely reported in many studies from various perspectives. These perspectives include sport involvement, enjoyment, and withdrawal, athlete satisfaction; athletes' physical and psychological status; optimal sport performance; and successful sport performance. The majority of research in sport leadership has focused on the coach, with particular emphasis on personality traits, behavioural attributes, and situational determinants. The current study focuses on a comparison of coach leadership preferences of athletes in South Africa and India. The study used a quantitative research approach using the Leadership Scale for Sport (LSS) to collect data from student-athletes in South Africa and India. There were 221 South African participants with ages ranging between 18 years and 60 years $(M=23.8, S D=6.0)$. On the other hand, there were 400 Indian participants with ages ranging between 18 years and 25 years $(M=21.4, S D=2.1)$. To analyse data, descriptive statistics in terms of means and standard deviations were computed. Comparisons of different variables between the two countries were determined through computing unpaired samples t-tests. The results revealed that Indian participants had higher mean scores for all the leadership behaviour preferences compared to their South African counterparts. In fact, all the means were statistically significant $(p<0.0001)$. It is concluded that athletes in India appear not to set the bar too high regarding their preferences and expectations of their coaches compared to South African athletes.
\end{abstract}

\section{Introduction}

Globally sport has emerged into an immensely lucrative and highly competitive market which churns huge amounts of revenue. The key players in the industry are the sport organisations, the fans and sponsors. Within the sport organisations athletes and sport coaches play a huge role in producing a service for sport consumers. Without these two critical 'players' it is highly unlikely that any sport event would ever be staged. The athlete-coach relationship is a vertical dyadic relationship in which the coach plays a critical leadership role. Many studies (e.g. Horn, 2008; Riemer, 2007; Kent \& Chelladurai, 2001; Riemer \& Chelladurai, 1998; Chelladurai \& Saleh, 1980) refer to coaches as leaders. Research on leadership has been conducted in a variety of disciplines such as psychology, history, philosophy, education, political science, theology, industry, and sport (Klenke, 1993).

The direct influence of coaches on their athletes has been widely reported in many studies from various perspectives. These perspectives include sport involvement, enjoyment, and withdrawal (Liukkonen, 1999), athlete satisfaction (Riemer \& Chelladurai, 1995); athletes' physical and psychological status (Reinboth, Duda, \& Ntoumanis, 2004; Serpa, 1999); optimal sport performance (Vealey, 2005); and successful sport performance (Riemer \& Chelladurai, 1998). In most studies which explored the coach-athlete relationship, the critical role of the coaches' leadership behaviour has been hugely attested to. The majority of research in sport leadership has focused on the coach, with particular emphasis on personality traits, behavioural attributes, and situational determinants (Chelladurai, 1984; Dupuis, Bloom \& Loughead, 2006). The current study focuses on coach leadership preferences of athletes.

Consensus has not yet been reached on a universal conceptualization of leadership (Loughead, Hardy \& Eys, 2006). This may perhaps be due to the complexity of the leadership construct. Mannie (2005) defines leadership as the ability to influence human behaviour, bring everyone together for a common cause, delegates responsibility, takes ownership of the programme, and work with a purpose. Riemer (2007), on the other hand, describes leadership as a phenomenon that deals with group dynamics and interpersonal communication. Its effectiveness is determined by the relationship between factors such as coach and athlete behaviour, situational factors and athlete characteristics (Horn, 2008). 
For well over two decades the most prominent, researched and discussed leadership model in sport was the Multidimensional Model of Leadership (MML) (Chelladurai \& Carron, 1978), which comprises elements of several leadership theories from other disciplines. The MML focuses upon three states of leader behaviour which determine leadership effectiveness. These are: 1) the actual coaching behaviour which includes what is done or can be done to influence athletes; 2 ) required behaviour which is behaviour prescribed by the situation and 3) preferred behaviour which is the type of behaviour that athletes would like from their coaches. The main concern with the MML was the compatibility between coach and athlete which is dependent on the degree of congruence among the afore-mentioned three states of leadership behaviour. Previous studies on leadership in sport (e.g. Horn, 2008; Riemer, 2007; Kent \& Chelladurai, 2001; Mondello \& Janelle, 2001; Riemer \& Chelladurai, 1998; Chelladurai \& Saleh, 1980; Chelladurai \& Saleh, 1978) have adopted the MML as a source model to identify the most effective leadership styles adopted by sport coaches.

Arising from the MML, Chelladurai and Saleh (1980) developed the Leadership Scale for Sports (LSS), an inventory that measures five dimensions of leader behaviour, namely training and instruction, democratic, autocratic, social support, and positive feedback. This scale examined the relationships in the MML, taking into account situational, leader and team member characteristics. These variables are believed to influence three states of leader behaviour; namely required, preferred, and actual (Dupuis et al., 2006). Several other studies were conceptualized from the LSS (e.g. Riemer \& Chelladurai, 1998; Martin \& Barnes, 1999, Kozub \& Pease, 2001; Loughead \& Hardy, 2005). The current study adopted the LSS to examine and compare coach leadership behaviour preferences of student athletes from India and South Africa.

Kent and Chelladurai (2001) asserted that leadership is an important determinant of effective functioning for any sport organisation or team. Success in sport coaching depends, to a large extent, on the leadership style of the coach. Despite this assertion, leadership research, especially on the coach-athlete relationship is sparse, peripheral and sporadic (Loughead et al., 2006; Riemer \& Chelladurai, 1998). The student-athlete represents an important member of the sport leadership dyad. The complex and multifaceted nature of the coach-athlete interpersonal relationship is intriguing and often little understood. Coaches, in their leadership role, have an enormous influence on athletes' physical and psychological status (Reinboth et al., 2004; Serpa, 1999).

\section{Theoretical framework}

Leadership has been researched from various theoretical perspectives. One of the dominant theories used previously was the contingency theory (Yashfro, 2008). The underlying theme of this theory is based on the fact that leadership is contingent on bringing into sync leadership style and situational favourableness. The basic premise of this theory is that leadership styles are not generically effective across all situations. The contingency theory focuses on the relations between the situation of leaders' work (in this study the coach's job) and their actions, goals, and behaviours (Spillane, Halverson \& Diamond, 2004; Fiedler 1970). The assumption is that that there is no one best approach to coaching and the most effective method of coaching depends on organisational factors and the athletes themselves.

Some researchers have focussed on such situational aspects as relations between coaches and athletes while others concentrated on the athletes and the extent to which the coaching task is structured as well the athlete's preparedness to achieve the coach's goal. The contingency theory assumes that for coaching to be effective, coaches need to draw on a repertoire of styles which respond to the coach's leadership style, the situation and the receptiveness of athletes.

The normative decision theory was derived from the contingency theory (Chemers, 2000). Leadership effectiveness is achieved through the integration of coaches' strategies and situational factors. In this approach coaches can either be autocratic, i.e. make unilateral decisions; consultative, i.e. taking into account the input of athletes; or participative, i.e. creating a situation in which both the coach and athlete arrive at a decision together (Yashfro, 2008). In this approach it is hypothesized that the most effective decision making style is dependent on the clarity and structure of the coaching activity; the degree of support from athletes and the sport organization; the timeframe for coaches to make decisions and the level of conflict among athletes. The leadership style that the coach will adopt is dependent on any of the afore-mentioned situations. While the normative theory has not been empirically tested to make judgments in an athletic context (Riemer \& Chelladurai , 1998), it is still relevant in the sporting context.

\section{Multidimensional Nature of the Coaching Job}

Coaches have received the most attention from sport leadership researchers because of the multifaceted nature of the 
responsibilities they assume. They spend a considerable amount of time training and counselling the athletes in their charge. They fulfil multiple roles such as setting goal priorities, developing skills, analysing tactics and techniques, and adjusting their behaviours to meet individual needs (Smoll \& Smith, 1989). They are often called upon to develop significant relationships with athletes, assistant coaches, and managers (Jowett, 2003). They also take responsibility for making final decisions in numerous team related issues such as strategy, tactics, and team personnel (Loughead et al., 2006). At colleges and universities they are expected to guide and counsel student-athletes who have academic concerns, social difficulties, or career decisions. Coaches also have the responsibility of building sound positive relationships with their athletes because they have "a great impact on the athletes' training processes, performance outcomes, and many aspects of their personal lives" (Poczwardowski, Barott \& Henschen, 2002:117). Coaches play a significant role in the physical and psychological development of their athletes (Gould, Dieffenbach \& Moffett, 2002) as well as contribute to their overall sport performance (Horn, 2002).

In order to bring about improvement in athletic performance, it may be necessary for the coach to engage in coaching behaviours to which athletes are receptive. What may be an appropriate coaching behaviour to one athlete may be an ineffective approach for another. Similarly, specific behaviour by the coach may be more productive of certain outcomes than others (Tinning, 1982). Different needs and preferences from individual athletes within the team confront coaches of team sports. The coach may adopt either a homogenous approach that treats all athletes equally, or alternatively create a heterogeneous style that provides differential treatment to individual athletes. As a result of this, it is important for the coach to be aware of the coaching preferences of his/her athletes in order to provide satisfactory experiences and improve athletic performance. According to Chelladurai and Carron (1983), if a coach adapts his or her behaviour to comply with the athletes' preferred behaviour, the athlete may be more readily inclined to repay the coach through improved performance.

\section{Significance of the Study}

The study will contribute to the body of knowledge and understanding of leadership qualities as perceived by the studentathletes. Furthermore the results of this study could help better predict student-athletes' preferred leadership behaviour of their coaches. By modifying and adapting their behaviour in relation to athlete preferences, coaches could build congruence between preferred and actual behaviours which could ultimately result in improved performance and satisfaction among student-athletes. The findings of the study could also contribute to the development of improved coaching and training programmes.

\section{Purpose of the Study}

Considering the fact that coaches are often referred to as leaders who define, supply, and deliver the sport experience for the athlete (Surujlal \& Dhurup, 2011), it is important that for coaches to be aware of the leadership behaviour preferences of the athletes in their charge. The purpose of this study was therefore to identify and compare the leadership behaviour preferences of student-athletes from tertiary institutions in South Africa and India. This means that there were two questions investigated here. The first was: what are the leadership behaviour preferences of student athletes from the two countries? The second was: is there a difference between South African and Indian students' leadership behaviour preferences with respect to their measured biographical variables. The comparisons here were for preferences of students belonging in a specific group. For instance, in terms of gender, females were compared to each other while with regard to the preferred age of the coach; specific age categories in each country were compared. The specific sub-questions constituting the second question was: is there a statistically significant difference between the two countries in respect of:
a. Each country and each of Training and instruction, Democratic behaviour, Autocratic behaviour, Social support, and Positive feedback
b. Gender and each of Training and instruction, Democratic behaviour, Autocratic behaviour, Social support, and Positive feedback
c. Years in competitive sport and each of Training and instruction, Democratic behaviour, Autocratic behaviour, Social support, and Positive feedback
d. Preferred coach and each of Training and instruction, Democratic behaviour, Autocratic behaviour, Social support, and Positive feedback
e. Age of preferred coach and each of Training and instruction, Democratic behaviour, Autocratic behaviour, 


\section{Social support, and Positive feedback}

\section{Research methodology}

An extensive literature study on leadership in sport was undertaken to develop the theoretical framework for the study. In addition, the study adopted a quantitative research approach which involved the administration of questionnaires to student-athletes at different tertiary institutions in India and South Africa.

\subsection{Sample}

The sample for the study comprised student-athletes. For purposes of this study the student-athlete is regarded as an individual who is a skilled performer who participates competitively in sport and was eligible to participate in interuniversity/college sports. In India the subjects for the present investigation were selected from tertiary institutions in Kerala, South India. In South Africa, the subjects were selected from two universities in the Gauteng Province. In both instances the sample size comprised 400 student-athletes.

\subsection{Instrument}

In this study, the Leadership Scale for Sports (LSS) (Chelladurai \& Saleh, 1980) was used to collect data. This scale is made up of 40 items grading athlete's leadership preferences on a 5-point Likert scale ranging from 1 (Always) to 5 (Never). The scoring of each item was as follows: $5=$ Never; $4=$ Seldom (about $25 \%$ of the time); $3=$ Occasionally (about $50 \%$ of the time); 2 = Often (about $75 \%$ of the time); 1 = Always. Each item was prefaced with the words 'I prefer my coach to. .' The instrument comprised 5 subscalesnamely Training and Instruction (13 items); Democratic Behaviour (9 items); Autocratic Behaviour (5 items); Social Support (8 items); and Positive Feedback (5 items). In terms of the reliability of the LSS from athletes' perceptions, alpha values as measures of internal consistency were reported in a study conducted among Canadian athletes (Chelladurai \& Saleh, 1980). The values were: Training and Instruction ( $a=$ .93); Democratic Behaviour ( $\alpha=.87)$; Autocratic Behaviour ( $\alpha=.79)$; Social Support $(\alpha=.86)$; and Positive Feedback ( $\alpha$ $=.92$ ). Studies conducted in Japan and Canada reported similar alpha values as shown in Table 1.

Table 1. Internal consistency estimates for athletes' perception version of the LSS for each subscale*

\begin{tabular}{lccc}
\hline & Japan & & Canada \\
\cline { 2 - 2 } Subscale & $\mathrm{a}$ & $\mathrm{a}$ \\
\hline Training and Instruction & .89 & .88 \\
Democratic Behaviour & .81 & .75 \\
Autocratic Behaviour & .57 & .59 \\
Social Support & .84 & .84 \\
Positive Feedback & .81 & .91 \\
\hline from Chelladurai, Imamura, Yamaguchi, Oimnuma, \& Miyauchi (1988)
\end{tabular}

In terms of the validity of the LSS, content validity was reported where the subscales of the LSS were found to be consistent with literature on leadership as described in the construction of the questionnaire (Chelladurai \& Saleh, 1980). Factorial validity in which items had similar factor structure across three samples was also reported by Chelladurai (1990)

\subsection{Procedure}

In India the questionnaire was administrated to the subjects by Masters graduate residing in Kerala. In South Africa trained fieldworkers were used to administer the questionnaire to participants. Participants were identified at different stadia at which they trained. Participants were informed through a covering letter that their participation was voluntary could be discontinued at any time without repercussions, their responses would be confidential and their participation would remain anonymous. In most instances the questionnaires were completed in the presence of the fieldworker or researcher after training sessions. In other instances they were completed by the student-athletes at their convenience and later collected by the fieldworker or researcher. 


\subsection{Data analysis}

To analyse data, descriptive statistics in respect of the 5 subscales of the LSS were computed using the statistical package for social sciences (SPSS - version 20). That is, means and standard deviations were computed for each of the subscales, Training and Instruction; Democratic Behaviour, Autocratic Behaviour, Social Support; and Positive Feedback. Following the computation of the descriptive statistics, comparisons of means from the two countries in respect of the five subscales were determined by calculating unpaired samples t-tests. The unpaired samples t-tests were computed using GraphPad Software (c) (2013). Further, comparisons between the two countries involving the subscales were evaluated against variables such as gender, competitive sport in years, the preferred gender of the coach, and the preferred age of coach. All the tests were computed with the significance level set at $p<0.0001$.

\section{Results and Discussion}

The results presented here are in the following order: first the biographical data of both the South African and Indian participants is provided. This is followed by a presentation of the reliability and validity of data from the two countries. Reporting the reliability and validity is important because without this being acceptable, it makes it difficult to draw reasonable conclusions about the collected data. The final section of the results deals with the two questions addressed in the study. Firstly, the preferences of the participants from both countries are reported. Secondly, the results of the different comparisons in respect of the biographical data against the LSS subscales are reported.

\subsection{Biographical Information}

There were 221 South African and 400 Indian participants. In terms of the year of study, first years were 80 (36.2\%) in South Africa and 276 (69.0\%) in India; second years were 76 (34.4\%) in South Africa and 107 (26.7\%); third years were $56(25.3 \%)$ in South Africa and $17(4.3 \%)$ in India. There were 9 postgraduate students from South Africa while none participated from India. The ages of the South Africans ranged between 18 years and 60 years $(M=23.8, S D=6.0)$ while those of the Indian participants were between 18 years and 25 years $(M=21.4, S D=2.1)$. In fact, the participants were in a similar age range with a few outliers older than 25 years constituting about $0.5 \%$ of the South Africans.

A more comprehensive illustration of the biographical data is provided in Table 2. The table shows that males were in the majority in both countries. In fact, in both counties the males comprised more than half the participants, that is 141 (63.8\%) in South Africa and 217 (54. 2\%) in India respectively. Regarding the number of years that participants had been involved in sport, 56.5\% in South Africa and $39.0 \%$ in India indicated that this had been the case for five years or more. In terms of the level of study, more participants were in their first or second year at university. Specifically, $70.6 \%$ in South Africa and $95.7 \%$ in India were in their first or second year of study. In both countries, a majority of participants (56.6\% in South Africa; $52.5 \%$ in India) revealed that it did not matter to them whether a coach was male or female. Approximately a third of the participants in each country (34.4\% in South Africa; $32.8 \%$ in India) indicated that they had no preference in respect of the age of their coach. In South Africa however, a preference for a coach in the age range of 31 years - 40 years, was also expressed by $32.6 \%$ of the participants.

Table 2. Frequency and percentage distribution of the rest of South African and Indian participants' biographical data

\begin{tabular}{lcccc}
\hline \multirow{2}{*}{ Category } & \multicolumn{2}{c}{ South Africa } & \multicolumn{2}{c}{ India } \\
\cline { 2 - 5 } & $\mathrm{N}$ & $\%$ & $\mathrm{~N}$ & $\%$ \\
\hline Gender & 141 & 63.8 & 217 & 54.2 \\
$\quad$ Male & 80 & 36.2 & 183 & 45.8 \\
$\quad$ Female & & & & \\
\hline Years in competitive sport & 32 & 14.5 & 98 & 24.5 \\
1 Year & 23 & 10.4 & 77 & 19.3 \\
2 Years & 22 & 10.0 & 30 & 7.5 \\
Y Years & 19 & 8.6 & 39 & 9.8 \\
4 Years & 17 & 7.7 & 156 & 39.0 \\
5 Years & 21 & 9.5 & - & - \\
6 Years & 87 & 39.3 & - & - \\
More than 6 Years & & & &
\end{tabular}

Preferred coach 


\begin{tabular}{lcccc} 
Male & 64 & 29.0 & 84 & 21.0 \\
Female & 32 & 14.5 & 106 & 26.5 \\
It does not matter & 125 & 56.6 & 210 & 52.5 \\
\hline Age of preferred coach & & & & \\
20 - 30 Years & 49 & 22.2 & 65 & 16.3 \\
31 - 40 Years & 72 & 32.6 & 91 & 22.8 \\
41 - 50 Years & 22 & 10.0 & 56 & 14.0 \\
51 Years and older & 2 & .9 & 57 & 14.3 \\
It does not matter & 76 & 34.4 & 131 & 32.8 \\
\hline
\end{tabular}

\subsection{Reliability and Validity of the Instrument}

If a Likert-type scale is used to collect data, it is then opined that "... it is imperative to calculate and report Cronbach's alpha coefficient for internal consistency reliability for any scales or subscales one may be using" (Gliem \& Gliem, 2003: 89). Following this view, reliability of the Leadership Scale for Sport was determined by computing Cronbach's (1951) alpha which is a measure of internal consistency related to the interrelatedness of test items (Schmitt, 1996). Based on the rule of thumb "... $\geq .9$ - Excellent, $\geq .8$ - Good, $\geq .7$ - Acceptable, $\geq .6$ - Questionable, $\geq .5-$ Poor, and $\leq .5-$ Unacceptable" (George \& Mallery, 2003: 231) the computed values were: $\alpha=.91$ in South Africa and it was adjudged to be excellent and $a=.86$ in India meanwhile was good.

Table 3 shows the alpha values together with confidence intervals for the instrument and its subscales. In both the South African and Indian contexts Autocratic behaviour had alpha values that were very low. Nonetheless these values were consistent with values computed in other studies, for example in Japan and Canada, already mentioned here (see Table 1). Validity in this study was accepted a priori. This is because comprehensive explanations of the construction of the questionnaire together with issues relating its validity (Chelladurai, 1990; Chelladurai \& Saleh, 1980) were found to be adequate for the purposes of this study.

Table 3. Alpha values and confidence intervals from the Leadership Scale for Sport and its subscales

\begin{tabular}{lllllll}
\hline & \multicolumn{2}{c}{ South Africa } & & \multicolumn{2}{c}{ India } \\
\cline { 2 - 3 } \cline { 6 - 7 } & \multicolumn{2}{c}{$\mathrm{a}$} & $\mathrm{Cl}$ & & $\mathrm{a}$ & $\mathrm{Cl}$ \\
\hline Leadership Scale for Sport & .91 & $.89-.93$ & & .86 & $.84-.88$ \\
Training and instruction & .86 & $.83-.89$ & & .76 & $.72-.79$ \\
Democratic behaviour & .75 & $.70-.79$ & & .72 & $.68-.76$ \\
Autocratic behaviour & .48 & $.38-.57$ & & .42 & $.34-.50$ \\
Social support & & .75 & $.70-.80$ & & .78 & $.67-.72$ \\
Positive behaviour (Rewarding behaviour) & .86 & $.83-.89$ & & .73 & $.69-.77$ \\
\hline
\end{tabular}

\subsection{Preferences and test of significance}

Regarding leadership behaviour preferences of student athletes from the two countries, Positive behaviour ( $M=1.982$, $S D=0.83)$ was the most preferred while Autocratic behaviour $(M=2.903, S D=0.76)$ was the least preferred among South African participants. On the other hand, Democratic behaviour $(M=3.648, S D=0.51$ ) was the most preferred while Positive behaviour $(M=3.941, S D=0.57)$ as well as Social support $(M=3.945, S D=0.65$ ) were the least preferred from the Indian participants' perspective.

The first question was: is there a statistically significant difference between the two countries' participants with respect to each of training and instruction, democratic, autocratic, social support, and positive feedback? Here, determination of whether there were differences between scores obtained in each subscale of the Leadership Scale for Sport questionnaire was made. Table 4 shows that there were statistically significant differences between South African and Indian participants with respect to each of the subscales. In fact, the table shows that in all instances the Indian participants had higher mean scores than their South African counterparts. This is also reflected in the results of all the other questions regarding coach behaviour preferences.

The higher mean scores with regard to all the subscales for Indian participants are indicative of their lower leadership behaviour preferences in terms of all the subscales. Athletes in India appear not to set the bar too mhigh regarding their preferences and expectationsof their coaches. In south Africa the hosting of mega sport events such as the FIFA world Cup, the T20 Cricket Cup and the IRB Rugby World Cup has sparked increased interest and participation 
in sport. There has been a simultaneous corresponding increase in the preferences and expectations of athletes who attempt to emulate their sport heroes.

Table 4. Means, standard deviations and unpaired t-test score comparisons for the different subscales in South Africa and India

\begin{tabular}{|c|c|c|c|c|c|c|}
\hline \multirow[b]{2}{*}{ Subscale } & \multicolumn{2}{|c|}{ South Africa $(\mathrm{N}=221)$} & \multicolumn{2}{|c|}{ India $(\mathrm{N}=400)$} & \multirow[b]{2}{*}{$t$} & \multirow[b]{2}{*}{$d f \star \star$} \\
\hline & $\mathrm{M}$ & SD & $\mathrm{M}$ & SD & & \\
\hline Training and instruction & 2.105 & 0.70 & 3.715 & 0.50 & $33.14^{*}$ & 619 \\
\hline Democratic behaviour & 2.451 & 0.71 & 3.648 & 0.51 & $24.26^{*}$ & \\
\hline Autocratic behaviour & 2.903 & 0.76 & 3.753 & 0.62 & $15.15^{*}$ & \\
\hline Social support & 2.531 & 0.67 & 3.945 & 0.65 & $25.80^{*}$ & \\
\hline Positive behaviour & 1.982 & 0.83 & 3.941 & 0.57 & $34.55^{*}$ & \\
\hline
\end{tabular}

In terms of the leadership behaviour preferences of student athletes, it was found that male and female mean scores were not different within each country. This suggests that participants' preferences according to gender were not different. The second question was: is there a statistically significant difference between the two countries in respect of gender and each of training and instruction, democratic, autocratic, social support, and positive feedback? In relation to gender, there were 141 males and 80 females in South Africa while there were 217 males and 183 females in India. Table 5 reveals that irrespective of gender Indian participants had statistically significant differences compared to their South African counterparts. For example in the case of Training and instruction preferences for males a statistically significantly difference was computed: $\mathrm{t}(356)=23.63, \mathrm{p}<0.0001$. Similarly, for females $\mathrm{t}(261)=23.76, \mathrm{p}<0.0001$.

Table 5. Means, standard deviations and unpaired t-test scores for the gender comparisons with respect to the different LSS subscales in South Africa and India

\begin{tabular}{|c|c|c|c|c|c|c|c|}
\hline \multirow[b]{2}{*}{ Gender } & \multirow[b]{2}{*}{ Subscale } & \multicolumn{2}{|c|}{ South Africa } & \multicolumn{2}{|c|}{ India } & \multirow[b]{2}{*}{$t$} & \multirow[b]{2}{*}{$d f \star *$} \\
\hline & & M & SD & $M$ & SD & & \\
\hline \multirow{5}{*}{ Males } & Training and instruction & 2.179 & .72 & 3.700 & .49 & $23.63^{*}$ & 356 \\
\hline & Democratic behaviour & 2.551 & .74 & 3.676 & .49 & $17.22^{\star}$ & \\
\hline & Autocratic behaviour & 2.881 & .77 & 3.751 & .62 & $16.18^{\star}$ & \\
\hline & Social support & 2.521 & .68 & 3.970 & .62 & $20.78^{*}$ & \\
\hline & Positive behaviour & 2.044 & .85 & 3.946 & .54 & $25.74^{\star}$ & \\
\hline \multirow{5}{*}{ Females } & Training and instruction & 1.976 & .63 & 3.734 & .51 & $23.76^{*}$ & 261 \\
\hline & Democratic behaviour & 2.271 & .63 & 3.615 & .52 & $18.04^{\star}$ & \\
\hline & Autocratic behaviour & 2.942 & .73 & 3.755 & .61 & $9.33^{*}$ & \\
\hline & Social support & 2.547 & .64 & 3.914 & .68 & $15.27^{*}$ & \\
\hline & Positive behaviour & 1.872 & .78 & 3.93 & .60 & $23.13^{*}$ & \\
\hline
\end{tabular}

${ }^{*} \mathrm{p}<0.0001 ;{ }^{* \star} \mathrm{df}=$ degrees of freedom. To avoid repetition the degrees of freedom are only on the first variable in all the tables

Regarding leadership behaviour preferences of student athletes from the two countries, there were 77 (34.8\%) participants who had been in competitive sport for less than 3 years and $144(65.2 \%)$ in competitive sport for 4 years or more in South Africa. In India there were 205 (51.2\%) and 195 (48.8\%) participants respectively. In South Africa, the mean scores for the five LSS subscales ranged between Positive behaviour ( $M=2.036, S D=0.76)$ and Autocratic behaviour ( $M=2.909, S D=0.76$ ) for participants who have been in competitive sport for less than 3 years. For participants in competitive sport for 4 years or more in South Africa the mean scores ranged between Positive behaviour $(M=1.953, S D=0.87)$ and Autocratic behaviour $(M=2.900, S D=0.76)$. On the other hand, in India mean scores ranged between Democratic behaviour $(M=3.634, S D=0.52)$ and Social support $(M=3.968, S D=0.62)$ for participants in competitive sport for less than 3 years. For participants in competitive sport for 4 years or more the mean scores ranged between Democratic behaviour $(M=3.663, S D=0.49)$ as well as Social support $(M=3.920, S D=0.68)$ and Positive behaviour ( $M=3.927, S D=0.57$ ). This was interpreted to suggest that in South Africa Positive behaviour was the least preferred while Autocratic behaviour was the most preferred among all the participants. In contrast, in India Democratic behaviour was the least preferred while Social support was the most preferred between both groups. Also preferred among participants who had been in competitive sport for 4 years or more, in India was Positive behaviour. 
Table 6. Means, standard deviations and unpaired t-test scores for the years in competitive sport comparisons with respect to the different LSS subscales in South Africa and India

\begin{tabular}{|c|c|c|c|c|c|c|c|}
\hline \multirow[b]{2}{*}{$\begin{array}{l}\text { Competitive } \\
\text { sport (Years) }\end{array}$} & \multirow[b]{2}{*}{ Subscale } & \multicolumn{2}{|c|}{ South Africa } & \multicolumn{2}{|c|}{ India } & \multirow[b]{2}{*}{$\mathrm{t}$} & \multirow[b]{2}{*}{$d f * *$} \\
\hline & & M & SD & M & SD & & \\
\hline \multirow{5}{*}{$1-3$ year } & Training and instruction & 2.153 & .69 & 3.717 & .48 & $21.42^{*}$ & \multirow[t]{5}{*}{280} \\
\hline & Democratic behaviour & 2.410 & .73 & 3.634 & .52 & $15.65^{*}$ & \\
\hline & Autocratic behaviour & 2.909 & .76 & 3.749 & .60 & $9.69 *$ & \\
\hline & Social support & 2.502 & .69 & 3.968 & .62 & $17.16^{*}$ & \\
\hline & Positive behaviour & 2.036 & .76 & 3.953 & .57 & $22.71^{*}$ & \\
\hline \multirow{5}{*}{4 years +} & Training and instruction & 2.080 & .70 & 3.713 & .53 & $24.50^{*}$ & \multirow[t]{5}{*}{337} \\
\hline & Democratic behaviour & 2.473 & .70 & 3.663 & .49 & $18.28 *$ & \\
\hline & Autocratic behaviour & 2.900 & .76 & 3.757 & .63 & $11.35^{*}$ & \\
\hline & Social support & 2.546 & .65 & 3.920 & .68 & $18.75^{*}$ & \\
\hline & Positive behaviour & 1.953 & .87 & 3.927 & .57 & $25.23^{*}$ & \\
\hline
\end{tabular}

* $p<0.0001 ;{ }^{*} \mathrm{df}=$ degrees of freedom

The third question was: Is there a statistically significant difference between the years in competitive sport and each of training and instruction, democratic, autocratic, social support, and positive feedback? In this instance there were 77 (34.8\%) participants who had been in competitive sport for 1 year to 3 years in South Africa and 205 (51.2\%) in India. Also, there were 144 (65.2\%) who had been in competitive sport for 4 years or more in South Africa while there were 195 (48.8) in India. It may be seen from Table 6 that in both groups of years in competitive sport, Indian participants had higher mean scores regarding each of the LSS subscales. The mean differences were also statistically significantly different. For instance in the group that had been in competitive sport for 1 year to 3 years the preference for Democratic behaviour had $t(280)=15.65, p<0.0001$. For the group that had been in competitive sport for 4 years or more the preference for Democratic behaviour reflected $t(337)=18.28, p<0.0001$.

In terms of leadership behaviour preferences of student athletes from the two countries, there were $37(16.7 \%)$ participants whose preference was a male coach in South Africa and $57(14.2 \%)$ in India. There were also 171 (77.4\%) whose preference was a female coach in South Africa while there were $244(61.1 \%)$ in India. Furthermore, there were 13 (5.9\%) participants to whom the gender of the coach did not matter in South Africa while there were 99 (24.7\%) in India. These results in essence reveal that in both countries a female coach was the most preferred by participants.

The fourth question was: is there a statistically significant difference between the gender of the preferred coach and each of training and instruction, democratic, autocratic, social support, and positive feedback? Table 7 shows that Indian participants had higher mean scores than their counterparts in South Africa. In fact, in all instances statistically significant differences between the gender of the preferred coach and each of training and instruction, democratic, autocratic, social support, and positive feedback were established. For example, in the case where the preference was for a male coach regarding Autocratic behaviour, the statistically significant difference was computed as $t(92)=4.93 ; p<$ 0.0001 . On the other hand, for a female coach against Autocratic behaviour, $t(413)=12.57 ; p<0.0001$ while the same variable had values of $t(110)=7.22 ; p<0.0001$ for the participants to whom the gender of the coach did not matter.

Table 7. Means, standard deviations and unpaired t-test scores for the coach's preferred gender comparisons with respect to the different LSS subscales in South Africa and India

\begin{tabular}{|c|c|c|c|c|c|c|c|}
\hline \multirow[b]{2}{*}{ Coach gender } & \multirow[b]{2}{*}{ Subscale } & \multicolumn{2}{|c|}{ South Africa } & \multicolumn{2}{|c|}{ India } & \multirow[b]{2}{*}{$t$} & \multirow[b]{2}{*}{$d f * \star$} \\
\hline & & $\mathrm{M}$ & SD & $\mathrm{M}$ & SD & & \\
\hline \multirow{5}{*}{ Male } & Training and instruction & 2.000 & .40 & 3.619 & .55 & $15.46^{*}$ & \multirow[t]{5}{*}{92} \\
\hline & Democratic behaviour & 2.294 & .69 & 3.571 & .53 & $10.11^{*}$ & \\
\hline & Autocratic behaviour & 2.940 & .76 & 3.684 & .68 & $4.93^{\star}$ & \\
\hline & Social support & 2.513 & .68 & 3.882 & .65 & $9.83^{*}$ & \\
\hline & Positive behaviour & 1.730 & .49 & 3.86 & .64 & $17.25^{\star}$ & \\
\hline \multirow{5}{*}{ Female } & Training and instruction & 2.125 & .74 & 3.738 & .49 & $26.69^{*}$ & \multirow[t]{5}{*}{413} \\
\hline & Democratic behaviour & 2.501 & .71 & 3.678 & .50 & $19.86^{*}$ & \\
\hline & Autocratic behaviour & 2.925 & .75 & 3.779 & .63 & $12.57^{*}$ & \\
\hline & Social support & 2.569 & .65 & 3.939 & .67 & $20.83^{*}$ & \\
\hline & Positive behaviour & 2.028 & .89 & 3.930 & .56 & $26.69^{*}$ & \\
\hline
\end{tabular}




$\begin{array}{llllllll} & \text { Training and instruction } & 2.148 & .79 & 3.712 & .50 & 9.78^{\star} & 110 \\ & \text { Democratic behaviour } & 2.239 & .82 & 3.618 & .51 & 8.52^{\star} & \\ \text { Doesn't } & \text { Autocratic behaviour } & 2.508 & .78 & 3.729 & .54 & 7.22^{\star} & \\ \text { matter } & \text { Social support } & 2.067 & .75 & 3.995 & .60 & 10.63^{\star} & \\ & \text { Positive behaviour } & 2.092 & .70 & 4.012 & .56 & 11.22^{*} & \\ { }^{*} \mathrm{p}<0.0001 ;{ }^{* \star} \mathrm{df}=\text { degrees of freedom } & & & & & \end{array}$

Regarding leadership behaviour preferences of student athletes from the two countries, there were 121 (54.7\%) South African participants who preferred a coach who is less than 40 years compared to $156(39.1 \%)$ in India. Also, there were $24(10.9 \%)$ whose preference was a coach of more than 40 years in South Africa and $113(28.2 \%)$ in India. Finally, 76 (34.4\%) in South Africa and 131 (32.7\%) in India felt that the age of the coach did not matter to them. These results indicate that for South African participants a coach whose age was less than 40 year was more preferable. In India on the other hand the preference for a coach's age was not so clear cut. In fact, participants who preferred a coach less than 40 years were slightly more than one in three, those who preferred a coach of over 40 years were just over a quarter while those to whom the age did not matter were also slightly more than one in three.

The fifth question was: is there a statistically significant difference between the age of the preferred coach and each of training and instruction, democratic, autocratic, social support, and positive feedback? In terms of differences, Indian participants had statistically significant mean scores compared to the South African participants (see Table 8).

Table 8. Means, standard deviations and unpaired t-test scores for the preference of the coach's age comparisons with respect to the different LSS subscales in South Africa and India

\begin{tabular}{|c|c|c|c|c|c|c|c|}
\hline \multirow[b]{2}{*}{ Age of coach } & \multirow[b]{2}{*}{ Subscale } & \multicolumn{2}{|c|}{ South Africa } & \multicolumn{2}{|c|}{ India } & \multirow[b]{2}{*}{$\mathrm{t}$} & \multirow[b]{2}{*}{$d f \star \star$} \\
\hline & & $M$ & SD & $M$ & SD & & \\
\hline \multirow{5}{*}{40 years and less } & Training and instruction & 2.043 & .60 & 3.723 & .50 & $25.44^{*}$ & \multirow[t]{5}{*}{275} \\
\hline & Democratic behaviour & 2.360 & .69 & 3.626 & .51 & $17.55^{\star}$ & \\
\hline & Autocratic behaviour & 2.805 & .72 & 3.801 & .62 & $12.35^{*}$ & \\
\hline & Social support & 2.473 & .64 & 3.925 & .64 & $18.75^{\star}$ & \\
\hline & Positive behaviour & 1.949 & .72 & 3.909 & .57 & $25.35^{\star}$ & \\
\hline \multirow{5}{*}{ More than 40 years } & Training and instruction & 2.410 & .80 & 3.688 & .48 & $10.39^{*}$ & \multirow[t]{5}{*}{135} \\
\hline & Democratic behaviour & 2.606 & .55 & 3.635 & .52 & $8.63^{*}$ & \\
\hline & Autocratic behaviour & 2.850 & .65 & 3.678 & .57 & $6.26^{*}$ & \\
\hline & Social support & 2.615 & .70 & 3.961 & .60 & $9.64^{*}$ & \\
\hline & Positive behaviour & 2.300 & .94 & 4.018 & .52 & $12.47^{*}$ & \\
\hline \multirow{5}{*}{ Age doesn't matter } & Training and instruction & 2.108 & .79 & 3.727 & .53 & $17.67^{*}$ & \multirow[t]{5}{*}{205} \\
\hline & Democratic behaviour & 2.547 & .78 & 3.687 & .48 & $12.93^{*}$ & \\
\hline & Autocratic behaviour & 3.076 & .81 & 3.760 & .65 & $6.66^{*}$ & \\
\hline & Social support & 2.595 & .70 & 3.954 & .69 & $13.54^{*}$ & \\
\hline & Positive behaviour & 1.934 & .95 & 3.911 & .61 & $18.18^{*}$ & \\
\hline
\end{tabular}

${ }^{*} p<0.0001 ;{ }^{* *} \mathrm{df}=$ degrees of freedom

\section{Conclusion}

The findings of this comparative study indicate differences exist across all five subscales between the two countries regarding the leadership preferences of university athletes. . Various environmental influences such as political factors, social factors, organizational culture and available resources play a role in the way a coach is perceived. These perceptions could ultimately be the deciding factor in the coach leadership preferences of university athletes. Furthermore there exists anecdotal evidence to suggest that athletes in South Africa experience a sense of entitlement regarding the leadership they expect of sport coaches, hence their high levels of preference of leadership behaviours. In contrast, anecdotal evidence in India suggests that athletes are more subservient to their teacher/coach hence their leadership preferences are lower than those of their South African counterparts. 


\section{Acknowledgement}

The authors would like to acknowledge the assistance of R.S.Subin from National College (Arts \& Science), Manacadu, Trivandrum, Kerala, India.

\section{References}

Chelladurai, P. (1984). Discrepancy between preferences and perceptions of leadership behavior and satisfaction of athletes in varying sports. Journal of Sport Psychology, 6, 27-41.

Chelladurai, P. (1990). Leadership in sports: A review. International Journal of Sport Psychology, 21, 328-354.

Chelladurai, P. \& Carron, A.V. (1978). Leadership. Canadian association for health, physical education and recreation sociology of sport monograph series A, Calgary, AB: University of Calgary.

Chelladurai, P. \& Carron, A.V. (1983). Athletic maturity and preferred leadership. Journal of Sport Psychology, 5, 371-380.

Chelladurai, P. \& Saleh, S.D. (1978). Preferred leadership in sports. Canadian Journal of Applied Sport Sciences, 3, 85-92.

Chelladurai, P. \& Saleh, S.D. (1980). Dimensions of leader behavior in sports: Development of a leadership scale. Journal of Sport Psychology, 2, 34-45.

Chelladurai, P., Imamura, H., Yamaguchi, Y., Oimnuma, Y., \& Miyauchi, T. (1988). Sport leadership in a cross-national setting: The case of Japanese and Canadian university athletes. Journal of Sport \& Exercise Psychology, 10, 374-389.

Chemers, M.M. (2000). Leadership research and theory: A functional integration. Group Dynamics, 4, 37-43.

Cronbach, L.J. (1951). Coefficient alpha and the internal structure of tests. Psychometrika, 16, 297-334.

Dupuis, M., Bloom, G.A. \& Loughead, T.M. (2006). Team captains' perceptions of athlete leadership. Journal of Sport Behavior, 29(1), 60-78.

Fiedler, F.E. (1970). Leadership experience and leader performance: another hypothesis shot to hell. Organizational Behaviour and Human Performance, 5 (2), 1-14.

George, D. \& Mallery, P. (2003). SPSS for Windows step by step: A simple guide and reference. 11.0 update (4th ed.). Boston: Allyn \& Bacon.

Gliem, J.A. \& Gliem, R.R. (2003). Calculating, interpreting, and reporting Cronbach's alpha reliability coefficient for Likert-type scales. Available at: https://scholarworks.iupui.edu/bitstream/handle/1805/344/Gliem+\&+Gliem.pdf?sequence=1. Accessed on 2012/04/11.

Gould, D., Dieffenbach, K. \& Moffett, A. (2002). Psychological characteristics and their development in Olympic champions, Journal of Applied Sport Psychology, 14 (3), 172-204.

GraphPad Software. QuickCalcs http://graphpad.com/quickcalcs/CImean1.cfm.

Horn, T.S. (2002). Coaching effectiveness in the sport domain. In T.S. Horn, Advances in Sport Psychology (2nd ed.). (pp. 309-354). Champaign, III.: Human Kinetics.

Horn, T. (2008). Coaching effectiveness in the sport domain. In T. Horn (Ed.), Advances in Sport Psychology (3rd ed.). pp. 239-267). Champaign, L: Human Kinetics.

Jowett, S. (2003).When the honeymoon is over: A case study of a coach-athlete relationship in crisis. The Sport Psychologist, 17, 444460.

Kent, A. \& Chelladurai, P. (2001). Perceived transformational leadership, organizational commitment, and citizenship behavior: A case study in intercollegiate athletics. Journal of Sport Management, 15, 135-139.

Klenke, K. (1993). Meta-analytic studies of leadership: Added insights or added paradoxes. Current Psychology, 12, 326-343.

Kozub, S.A., \& Pease, D.G. (2001). Coach and player leadership in high school basketball. Journal of Sport Pedagogy, 7, 1-15.

Liukkonen, J. (1999). Coach's influence in young athletes' personality development. Portuguese Journal of Human Performance Studies, 12, 35-52.

Loughead, T.A. \& Hardy, J. (2005). An examination of coach and peer leader behaviors in sport. Psychology of Sport and Exercise, 6, 303-312.

Loughead, T.M., Hardy, J. \& Eys, M.A. (2006). The nature of athlete leadership. Journal of Sport Behavior, 29(2), 142-158.

Mannie, K. (2005). Tough love is in effect here! Perspectives on coaching and leadership. Coach and Athletic Director, 74(10), 68-70.

Martin, S.B. \& Barnes, K. (1999). Coaching Behavior Questionnaire. Unpublished manual, University of North Texas, Denton.

Mondello, M.J. \& Janelle, C.M. (2001). A comparison of leadership styles of head coaches and assistant coaches at a successful division I athletic program. International Sports Journal, 5, 40-49.

Poczwardowski, A., Barott, J.E. \& Henschen, K. P. (2002). The athlete and coach: Their relationship and its meaning. Results of an interpretive study. International Journal of Sport Psychology, 33(1), 116-140.

Reinboth, M., Duda, J.L. \& Ntoumanis, N. (2004). Dimensions of coaching behavior, need satisfaction, and the psychological and physical welfare of young athletes. Motivation and Emotion, 28, 297-313.

Riemer, H. (2007). Multidimensional model of coach leadership. In S. Jowett \& D. Lavallee (Eds.), Social Psychology in Sport (pp. 5773). Champaign, IL: Human Kinetics.

Riemer, H.A. \& Chelladurai, P. (1995). Leadership and satisfaction in athletics. Journal of Sport and Exercise Psychology, 17, $276-293$.

Riemer, H.A. \& Chelladurai, P. (1998). Development of the athlete satisfaction questionnaire. Journal of Sport and Exercise Psychology, 
20, 127-156.

Schmitt, N. (1996). Uses and abuses of coefficient alpha. Psychological Assessment, 8(4), 350-353.

Serpa, S. (1999). Relationship coach-athlete: outstanding trends in European research. Journal of Human Performance Studies, 12(1), 7-19.

Smoll, F.L. \& Smith, R.E. (1989). Leadership behaviors in sport: A theoretical model and research paradigm. Journal of Applied Social Psychology, 19, 1522-1551.

Spillane, J.P., Halverson, R. \& Diamond, J.B. (2004). Towards a theory of leadership practice: a distributed perspective. Journal of Curriculum Studies, 36(1), 3-34.

Surujlal, J. \& Dhurup, M. (2011). Athlete preference of coach's leadership style. African Journal for Physical, Health Education, Recreation and Dance, 18(1), 111-121.

Tinning, R. (1982). Improving coaches' instructional effectiveness. Sports Coach, 5, 37-41.

Vealey, R.S. (2005). Coaching for the inner edge (pp. 75-103). Morgantown, WV: Fitness Information Technology.

Yashfro, Y. (2008). Japanese translation and psychometric evaluation of the revised leadership scale for sport. Available at: http://vuir.vu.edu.au/15737/1/Yashiro_2008compressed.pdf. Accessed on 2012/02/21. 